\title{
Reality of Linguistic Competencies of Pre-Service and In-Service Female Physical Education Teachers in the Sultanate of Oman
}

\author{
Fatma Alkaaf $^{1}$, Durayra AlMaqbali ${ }^{1} \&$ Yousra Al-Sinani ${ }^{1}$ \\ ${ }^{1}$ College of Education, Sultan Qaboos University, Muscat, Sultanate of Oman \\ Correspondence: Fatma Alkaaf, School of Management, College of Education, Sultan Qaboos University, Muscat, \\ Sultanate of Oman. E-mail: alkaaf@squ.edu.om
}

Received: July 24, 2020 Accepted: August 28, 2020 Online Published: September 11, 2020

doi:10.5539/jel.v9n5p184 URL: https://doi.org/10.5539/jel.v9n5p184

\begin{abstract}
This study aims to identify the acquisition of linguistic competencies by pre-service physical education teachers at the College of Education, Sultan Qaboos University, and in-service physical education teachers in Muscat and Dhofar Governorates in Oman, as well as any statistical differences between these two groups. The population of the study consisted of 30 pre-service teachers and 28 in-service teachers. The observation card instrument was used to collect data. The results showed that the acquisition level of the linguistic competencies of pre-service physical education teachers was medium. However, the acquisition level of the linguistic competencies of in-service physical education teachers was high. Furthermore, there were significant differences between the acquisition level of linguistic competencies in pre-service and in-service teachers in favor of in-service teachers. Based on these findings, we recommend developing these competencies in pre-service teachers during the teacher education program by focusing particularly on planning, implementation, and assessment.
\end{abstract}

Keywords: linguistic competencies, pre-service physical education teachers, in-service physical education school teachers, professional development program

\section{Introduction}

Educational systems responsible for the preparation of young people need to be constantly reviewed in order to improve their internal efficiencies, choose the best inputs that are consistent with the educational reality, and ensure that the outputs meet their communities' level of goals. The competency-based movement applies to all educational levels. Indeed, it is an active movement that enables teachers to have a more positive and effective impact on their students, given their significant and important role inside the school.

In fact, enhancing teachers' level of essential competence is crucial. Thus, most countries around the world have made efforts to turn teaching into a profession because of the changes that have affected the nature of the teaching process. This change is an important, objective, and organized process and allows the teacher to act freely inside the classroom using educational methods that achieve the artistic and scientific competencies required (Berry \& Ginsberg, 1991). It is also based on the views and beliefs of an academic discipline (Davies \& Rogers, 2000), which encourages the teacher to employ competencies consistent with their personality, abilities, and tendencies inside the classroom.

The educational competencies needed by the teacher are widely recognized as important because they have a great impact on the role of the teacher. At the international level, the United Nations Educational, Scientific and Cultural Organization's (UNESCO) report on education for the twenty-first century highlighted the need to improve teachers' efficiency by adopting certain policies and measures, notably those ensuring that teachers' training before and during their service will allow them to provide sustainable education through the development of their academic and professional competencies on both a theoretical and practical level (Khazali \& Momani, 2010).

At the national level, the Ministry of Education in the Sultanate of Oman has developed a general framework for the educational competencies that should be acquired by students to improve their ability to acquire knowledge and share it with individuals and groups, apply academic knowledge, and implement it in all spheres of life as well as use linguistic skills to communicate with others, acquire scientific research skills, reflect, and self-evaluate (Ministry of Education, 2009).

Therefore, there has been an effort to educate, prepare, and provide teachers with essential competencies in order 
to allow them to perform their job successfully. Teacher education programs have varied between traditional programs based on the quantity of information to performance-based programs based on educational competencies. Perhaps the emergence of competency-based or performance-based teacher education programs in the United States in 1969 was in response to the growing dissatisfaction with educational curricula at that time. Lately, competency-based teacher education is deemed among the most prominent modern trends and is prevalent in educational and scientific situations in developed countries; it is known as one of the most effective methods to prepare and train pre-service and in-service physical education teachers and is a response to the traditional methods previously used in teacher education.

Recently, developing and training qualified teachers has been based on the most recent theories of learning and education, and competency-based teacher education programs have been based on analyzing the learning process to allow teachers to acquire a number of competencies. Both are a fundamental part of preparing teachers and aim to improve the possibility of their success (Showaiter, 2004).

Effective teaching requires the teacher to possess many competencies and skills related to their field of work. Twenty-first-century teachers must possess a precise knowledge of professional, specialized, cultural, and linguistic competencies (Dam, Schipper, \& Runhaar, 2010).

The views and opinions of educators regarding the definition of the term "competency" have varied widely. Zayton (2003, p. 41) defined it as "the overall behaviour that includes knowledge, skills, and tendencies after undergoing a specific programme whose impact is reflected in its performance by special measurement tools prepared for this purpose."

Based on the above, it can be said that competency is the behavior based on knowledge, attitudes, and skills that indicate the ability of the individual to practice and carry out a task in a certain manner and after taking a specific educational program.

As for linguistic competencies, they are defined as "providing learners with linguistic skills that enable them to understand the language, its rules, and grammars which control it and control the characteristics of its components" (Ruslan, 1998, p. 128). They also mean that a learner can practice specific linguistic skills easily and efficiently so that they will be able to listen, talk, read, and write according to the criteria of accuracy, fluency, clarity, and persuasion, as well as acquire an acceptable amount of language culture and general concepts (Ali, 2009).

From the above two definitions, it can be said that the linguistic competency of the student enables them to practice the four linguistic skills in terms of accuracy, fluency, clarity, and persuasion. Linguistic competencies cannot be achieved at once but are acquired gradually until they become a linguistic behavior, when before they had been merely linguistic knowledge. The teacher's keenness to acquire sufficient linguistic skills reflects their awareness of the importance of language and its roles in communication.

Abdul Rahim and Al-Shabatat (2003) emphasized the main role of language in our lives, especially in educational communication. A physical education teacher should be linguistically efficient because they not only teach but also deliver a message aimed at preparing a student who is proud of their language.

Competencies in the field of education and learning are divided into two types:

1) Teaching competencies: These comprise teaching behaviors and abilities that teachers can acquire to become part of their behavior that help them perform successfully in a teaching setting. These include lesson planning, implementation and evaluation, classroom management, and effective communication competencies.

2) Linguistic competencies: These refer to the knowledge and necessary linguistic competencies that teachers must acquire so that they will be able to teach (Breckett, 2004). This research focuses on these competencies.

We believe that the competencies in the field of physical education can be classified on the basis of specialization, so that the teacher has specialized competencies related to the specialization; educational competencies related to their teaching performance; and linguistic competencies in terms of the teacher's proficiency in the four linguistics skills, namely listening, speaking, reading, and writing.

This study is an attempt to determine the extent of pre-service physical education teachers' acquisition of linguistic competencies during their practicum in the partner schools.

\subsection{Perception of the Study}

According to the findings of the Language and Identity Conference, which was organized by the Ministry of Culture, Arts and Heritage of Qatar during 15-17 February 2009, there is a noticeable weakness in the linguistic competencies of students and teachers at Arabic universities. This linguistic weakness results from a lack of interest at universities to create a course promoting Arabic language skills to their students. We noticed during 
teaching practice for physical education students and teachers at the College of Education, Sultan Qaboos University, that there is an obvious weakness in the students and teachers' linguistic competencies. Therefore, this study will attempt to identify the extent of the acquisition of linguistic competencies by pre-service physical education teachers at the College of Education, Sultan Qaboos University. No similar study in this area has previously been conducted in Arab countries in general or in the Sultanate of Oman in particular. Thus, we aspire to propose a framework of an Arabic language skills course to improve pre-service and in-service physical education teachers' linguistic performance.

\subsection{Purpose of the Study}

The main purpose of this study is to investigate the reality of the linguistic competencies of pre-service physical education teachers at the College of Education, Sultan Qaboos University. Specifically, we intend to 1) identify the extent of in-service physical education school teachers' and College of Education, Sultan Qaboos University, pre-service teachers' acquisition of linguistic competences; 2) identify any statistical differences between these two groups; and 3) develop a proposal to improve Arabic language competencies for pre-service physical education teachers at the College of Education, Sultan Qaboos University. The questions guiding this study were:

1) To what extent do pre-service female physical education teachers at the College of Education, Sultan Qaboos University, and in-service female physical education school teachers possess linguistic competencies?

2) Are there any statistically significant differences in the linguistic competencies of pre-service female physical education teachers at the College of Education, Sultan Qaboos University, and in-service female physical education school teachers?

3) What is the proposed framework for improving the linguistic competencies of pre-service physical education teachers at the College of Education, Sultan Qaboos University?

\subsection{Importance of the Study}

The present study is significant in many ways:

1) It raises awareness among pre-service teachers about their linguistic competencies.

2) It contributes to the existing body of knowledge about pre-service physical education teachers' linguistic competencies.

3) It provides a framework for building an Arabic language skills course for pre-service physical education teachers at Arabic universities in general and at Sultan Qaboos University in particular.

\subsection{Rivew of Literture}

The introduction of competencies is one of the most prominent current trends in teacher education programs in most developed countries in the field of education. The competency-based teacher education program has several advantages. It is a selective program that takes the form of specific teaching competencies based on modern technology. It also provides the opportunity for each student to acquire teaching skills in an efficient and rapid manner (Hamdan, 2001).

The factors that led to the emergence of the notion of competencies can be summarized as follows (Al-Naqah, 2010):

1) The general sense of the futility of the traditional form of theoretical preparation programs due to the lack of correlation between what is learned and what is performed and practiced in the real world.

2) The emergence of the behavioral trend, which emphasizes the need to identify actions that help the learner to perform their duties, and to identify the most effective methods and tools to acquire these behaviors.

3) The tendency towards the conversion of theories and scientific foundations into educational competencies that have an impact on the performance of the learner.

4) The emergence of mini-education as a method of training teachers on some skills, where attention is focused on the use of skills in the educational process rather than verbal performance.

5) The emergence of the idea of goal-oriented education and measuring the achievement of goals through the performance of the learner.

6) The emergence of the idea that there is no single teaching method suitable for all teaching and learning situations.

7) The tendency toward the separation of education and self-learning. 
8) The change from the traditional view of the role of the teacher as solely a communicator of information to students to highlight their other roles.

These factors have led to the emergence and prevalence of the teacher preparation movement, and they have been adopted by many teacher education colleges and institutes in developed countries. Thus, they have become among the most prominent and widespread aspects of modern education. Moreover, researchers have started to apply them through various curricula. There are even several classifications of teacher competencies, among which, as mentioned by Tuaima (2006), is Bloom's Taxonomy:

- Cognitive competencies

- Affective competencies

- Psychomotor competencies

Madkoor (2011) indicated another classification of competencies based on the roles the teacher has to perform in the classroom. In light of this view, competencies can be classified as follows:

- Planning competencies

- Implementation competencies

- Assessment competencies

Marie (2003) classified competencies as follows:

- Cognitive competencies

- Performance competencies

- Achievement competencies

Performance competencies are the observable and measurable skills required to carry out the role of the teacher and achieve educational objectives. Based on the performance competencies, the competent teacher is not someone who possesses information but is rather someone able to deliver this information to the learner with little effort and in a short time. A teacher's knowledge is no longer a result of their own experiences, but is based on their ability to take the initiative at work, where the competencies should include knowledge, performance, and self-confidence. A teacher of physical education is one of the most important educational figures as they have the chance to have direct contact with the students. They are also a medium between the student's existing behavior and the behavior that they need to demonstrate. Moreover, they are able to plan their lessons and can, through their understanding and educational style, help the learner become more responsible for and aware of their education so as to be in harmony with the environment (Attia, 2007).

Physical education teaching is a process that requires many competencies in order to deliver it properly. These competencies represent the general competencies of teaching. The teaching of physical education depends mainly on its teachers being able to perform their job effectively. Moreover, teaching candidates should take those competencies into account and practice them so that they will be able to develop and reach their potential (Abu Harja, Zaghloul, \& Radwan, 2000).

In light of the above, and in order for physical education teachers to deliver their message in a correct and effective way, they should be equipped with sufficient competencies and teaching skills in order to enhance the teaching process and be given the chance to utilize all their abilities and potential to achieve their goals and attain satisfactory results.

Abdl-Rasheed (2011) classified physical education teachers' competencies into five types:

1) Cognitive competencies:

These are related to the actual information and skills necessary for the physical education teacher in all areas of their work.

2) Performance competencies:

These are the competencies demonstrated by the physical education teacher, including psychomotor skills. The performance of these skills depends on the teacher's previous acquisition of knowledge competencies.

3) Emotional competencies:

These refer to the physical education teacher's preparations, tendencies, attitudes, values, and beliefs. These competencies cover various aspects such as the teacher's self-confidence, attitudes towards the profession, and relationships with others. 


\section{4) Productivity competencies:}

These refer to the impact of the teacher's performance in the previous competencies in the field of education, i.e., the tangible output of actions, behaviors, knowledge, and tendencies.

5) Personal competencies:

These competencies relate to the personal aspects of school sports teachers and include their ways of thinking, emotions, interests, judgments, energy, enthusiasm, vitality, and sense of humor in teaching.

The Arab Bureau of Education for the Gulf States (2010) divided the competencies for teachers into three main areas:

1) General basic competencies:

These competencies are supposed to be available to all teachers regardless of their specialization and include three competencies (linguistic, numerical, and technical).

2) Educational basic competencies:

These include a set of knowledge and educational skills that is supposed to be present in all teachers to carry out the process of teaching in the classroom effectively.

3) Basic competencies in the specialization and the methods of teaching, which are dependent on the teacher's specialty.

Several research studies have examined physical education teachers' competencies. Although there are many studies that have examined linguistic competencies in a variety of educational disciplines, the issue of linguistic competencies for physical education teachers has not received sufficient attention. This study will present other studies that have dealt with the educational competencies of physical education teachers and the linguistic competencies of university students in all disciplines.

Among the studies aimed at determining the extent of physical education teachers' acquisition of teaching competencies is the study conducted by Al-Tawel and Al-Jaafreh (2017) to determine teaching competencies from physical education teachers' point of view. To this end, the researchers followed the descriptive survey approach in presenting, analyzing, and interpreting the results. The researchers also designed a questionnaire consisting of four fields: planning competencies, implementation competencies, personal and social competencies, and motivation competencies. The questionnaire was administrated to 127 teachers of physical education in Jordan. The study categorized the degree of the acquisition of teaching competencies as low, medium, and high. The lesson execution competency was the highest teaching competency acquired by the study sample, whereas the planning competency was the lowest. Statistically significant differences due to gender and scientific qualifications were also found.

In terms of studies that have been conducted on the linguistic competencies of university students, Wahabi (2016) studied the low level of Arabic language competency among university students at Blida University in Algeria. The researcher concluded that family and school factors were among the most influential in the decline of the Arabic language in university students. The issue of linguistic weakness was not only at the university stage but also at the early stages in which the student acquired language.

Hand (2014) conducted a study in the United States that attempted to understand the views of physical education student teachers regarding their teaching competencies while training in the field. It also aimed to identify the factors that influence students' assessment of the level of their teaching competencies. Hand designed two questionnaires: the first focused on the teaching competencies required for students of physical education, and the second focused on the extent to which the students recognized the potential factors that affected their assessment of their teaching competencies. The results of the study showed that the students' degree of acquisition of teaching competencies varied from medium to high. The results also showed that the most important factors that can affect students' effectiveness are teaching experiences, feedback, and observation of qualified teachers.

Khair (2014) presented a paper at the Third Arabic Language Conference in Dubai about the causes of the weakness in the Arabic language at colleges of education, as well as its effects and suggestions for improving it. The paper presented various reasons for the weakness, such as focusing on foreign language teaching, privatization of education, selective migration, and a poor economy. Khair had several suggestions to deal with this weakness - for example, focusing on Arabic grammar, requiring that the Arabic language be the teaching language in Arab countries, and providing training courses in Arabic language skills (oral and written) for Arabic language teachers. 
Al-Rawahi and Al-Hinai (2013) conducted a study aimed at determining the degree of acquisition of teaching competencies by male and female physical education teachers in the Sultanate of Oman. It also aimed to determine the relationship between the degree of teaching competency acquisition and the reason the teachers decided to teach physical education. The sample included 142 male teachers and 168 female teachers. The researchers used a questionnaire as the data collection tool. The results of the study showed an absence of statistically significant differences due to gender and region variables but the presence of statistical differences according to the type of teaching experience. The results of the study did not show any correlation between the degree of the study sample's acquisition of teaching competencies and the reason for their selection of physical education teaching as a profession.

In Algeria, Hattab (2013) investigated the factors affecting the low level of standard Arabic among 30 sociology students at Mohammed University. A descriptive approach was selected to guide the study, and a questionnaire was used to collect data from the participants. The results showed that the participants' perceptions of the factors behind their low level of Arabic were due to family and school factors. For example, the average educational level of parents, the use of nonstandard language in the family, the failure to provide books and stories for children, the teacher not correcting linguistic errors, and a lack of reading materials for university students were all identified as affecting participants' Arabic levels.

The study conducted by Stojanovic and Zdravkovic (2012) aimed at identifying the reality of teaching competencies among 92 physical education teachers in Serbia and the statistical differences according to the variables of gender, school level, and teaching experience. Their questionnaire included competencies related to teaching skills and knowledge, educational abilities, learner characteristics, planning, educational guidance, cooperation with the local community, and practical issues. The results indicated the significant presence of teaching competencies in the field of physical education among the study sample. The results also showed that there were no statistically significant differences in teaching competencies according to gender, school level, or teaching experience.

Hamdan (2011) conducted a study to identify the competencies necessary for teaching in the field of physical education from the point of view of physical education teachers. A questionnaire was applied to a sample of 100 male and female teachers in the Gaza Strip. The questionnaire consisted of 70 items pertaining to specific dimensions (personal and professional, planning and good performance of the lesson, formulation of objectives, management of the classroom and human relations, control, and evaluation). Accordingly, the study recommended reconsidering the preparation of physical education teachers in order to comply with the requirements of their students' age group.

Baleed (2009) conducted a study on the weakness of the Arabic language among students at Tezee Wzo University in Algeria and at Arabic universities in general. Baleed analyzed university courses and graduation notes and their impact on language achievement. The findings lead to some suggestions to deal with these problems, such as using standard Arabic in the classroom and instituting an Arabic language skills course for students in the first year at university.

The above review of pertinent literature and previous studies highlights the significance of our study, as it sheds light on the degree of physical education teachers' acquisition of teaching competencies, which is defined in this research as the actual ability of the student to practice the language- - listening, speaking, reading, and writing easily and accurately. To our knowledge, no previous studies on Arabic language competencies have been conducted on both student teachers and teachers of physical education, which distinguishes this study from others.

\section{Method}

\subsection{Design of the Study}

We used a descriptive study approach and collected data using an observation card instrument. The observation card instrument consisted of three dimensions: lesson planning, lesson implementation, and lesson assessment.

\subsection{Population of the Study}

The study population consisted of all physical education female pre-service teachers from the College of Education at Sultan Qaboos University $(\mathrm{n}=30)$ and in-service female physical education teachers $(\mathrm{n}=28)$ from Muscat and Dhofar Governorates.

\subsection{Data Collection}

We developed an observation card instrument to collect data. The items in the data collection instrument were inspired by the pertinent literature. The observation card consisted of 25 linguistic competencies. Items were 
grouped into three dimensions: planning, implementation, and assessment.

\subsubsection{Validity of the Instrument}

A jury of experts reviewed the observation card instrument to ensure its validity. The jury consisted of experts in teaching Arabic and in training others to teach Arabic. Necessary changes were then made to the instrument.

\subsubsection{Reliability of the Instrument}

The reliability of the observation card was established by calculating Cronbach's alpha. The coefficient of correlation was 0.92 , which is considered very appropriate, indicating that the observation card is a reliable measure.

Table 1. Reliability of each field on the observation card

\begin{tabular}{lll}
\hline Field & Number of Phrases & Reliability Coefficient \\
\hline Planning & 8 & 0.90 \\
Implementation & 12 & 0.93 \\
Assessment & 5 & 0.94 \\
Overall Reliability Coefficient of the Instrument & & 0.92 \\
\hline
\end{tabular}

Table 1 shows that the reliability coefficient for each field was high. The overall reliability coefficient for all fields was also high (0.92). We used the Pearson correlation coefficient to identify the correlation between the competencies. Table 2 explains the correlation coefficients between the study instrument's fields.

Table 2. Values of correlation coefficients between the instrument's fields

\begin{tabular}{llll}
\hline Field & Planning & Implementation & Assessment \\
\hline Planning & - & 0.75 & 0.70 \\
Implementation & 0.75 & - & 0.85 \\
Assessment & 0.70 & 0.85 & - \\
\hline
\end{tabular}

Table 2 indicates that the correlation coefficient values were high. These results indicate that the observation card was highly reliable.

\subsubsection{Data Analysis}

Specify the research design in the Method section. Were subjects placed into conditions that were manipulated, we personally observed the physical education student teachers and in-service teachers while they conducted their physical education lessons. Three lessons for each student and teacher were investigated. To answer our research questions, we adopted a 4-point scale representing the levels of mean scores (Table 3).

Table 3. Levels of the mean scores on a 4-point scale

\begin{tabular}{ll}
\hline Mean Scores & Level \\
\hline Less than 2 & Not available \\
Between 2 and 2.5 & Low \\
Between 2.6 and 3 & Medium \\
More than 3 & High \\
\hline
\end{tabular}

Descriptive statistics, including means and standard deviations, were used to illustrate the pre-service physical education teachers' linguistic competencies. An independent sample t-test was carried out to examine the differences in the linguistic competencies of both groups of participants. Data was analyzed using SPSS software.

\section{Results and Discussion}

\subsection{Findings and Discussion Related to the First Question}

Our first research question investigated the extent to which pre-service female physical education teachers at the College of Education, Sultan Qaboos University, and in-service female physical education school teachers possess linguistic competencies. To answer this question, the frequencies, percentages, mean scores, and standard deviations for each language competency were calculated, as shown in Table 4. 
Table 4. Mean scores and standard deviations of the acquisition of linguistic competencies by pre-service and in-service physical education teachers

\begin{tabular}{|c|c|c|c|c|c|c|c|c|}
\hline \multirow[t]{2}{*}{ Field } & \multirow[t]{2}{*}{ No. } & \multirow[t]{2}{*}{ Item } & \multicolumn{3}{|c|}{ Pre-service ysical student teachers $(\mathrm{n}=30)$} & \multicolumn{3}{|c|}{ In-service teachers $(\mathrm{n}=28)$} \\
\hline & & & Mean & $\begin{array}{l}\text { Standard } \\
\text { Deviation }\end{array}$ & $\begin{array}{l}\text { Competency } \\
\text { Acquisition } \\
\text { Degree }\end{array}$ & Mean & $\begin{array}{l}\text { Standard } \\
\text { Deviation }\end{array}$ & $\begin{array}{l}\text { Competency } \\
\text { Acquisition } \\
\text { Degree }\end{array}$ \\
\hline \multirow[t]{8}{*}{ Planning } & 1 & $\begin{array}{l}\text { Correct formulation of the behavioral } \\
\text { objectives }\end{array}$ & 2.38 & 0.747 & Low & 3.46 & 0.508 & High \\
\hline & 2 & $\begin{array}{l}\text { Correct writing of the lesson's } \\
\text { components }\end{array}$ & 2.87 & 0.776 & Medium & 3.54 & 0.838 & High \\
\hline & 3 & $\begin{array}{l}\text { Ability to maintain the aesthetic of } \\
\text { writing in terms of shape, tidiness, and } \\
\text { cohesion between letters, words, and } \\
\text { lines }\end{array}$ & 2.80 & 0.551 & Medium & 3.54 & 0.838 & High \\
\hline & 4 & $\begin{array}{l}\text { Use of punctuation marks while writing } \\
\text { activities }\end{array}$ & 2.17 & 0.747 & Low & 3.29 & 0.845 & High \\
\hline & 5 & $\begin{array}{l}\text { Writing the lesson's components in a } \\
\text { clear way }\end{array}$ & 2.73 & 0.868 & Medium & 3.54 & 0.793 & High \\
\hline & 6 & $\begin{array}{l}\text { Writing the educational and practical } \\
\text { steps in sentences ranging from the } \\
\text { easiest to the hardest }\end{array}$ & 3.37 & 0.718 & High & 3.71 & 0.460 & High \\
\hline & 7 & $\begin{array}{l}\text { Correct use of linking words in the } \\
\text { different sections of the lesson }\end{array}$ & 2.30 & 0.988 & Low & 3.43 & 0.742 & High \\
\hline & 8 & Writing assessment activities correctly & 2.73 & 0.538 & Medium & 3.00 & 0.943 & High \\
\hline Means Total & & & 2.73 & 0.320 & Medium & 3.45 & 0.410 & High \\
\hline \multirow[t]{12}{*}{ Implementation } & 9 & $\begin{array}{l}\text { Use of standard Arabic to perform the } \\
\text { lesson }\end{array}$ & 2.17 & 0.747 & Low & 3.14 & 0.756 & High \\
\hline & 10 & $\begin{array}{l}\text { Correct articulation of letters during the } \\
\text { lesson }\end{array}$ & 2.80 & 0.664 & Medium & 3.82 & 0.476 & High \\
\hline & 11 & $\begin{array}{l}\text { Use of correct linguistic terms to control } \\
\text { and manage the classroom }\end{array}$ & 2.93 & 0.691 & Medium & 3.71 & 0.535 & High \\
\hline & 12 & $\begin{array}{l}\text { Gradual implementation of educational } \\
\text { and practical steps from easiest to } \\
\text { hardest consistent with the learners' } \\
\text { abilities }\end{array}$ & 3.13 & 0.730 & High & 3.71 & 0.535 & High \\
\hline & 13 & $\begin{array}{l}\text { Use of motivational words in the correct } \\
\text { way }\end{array}$ & 2.90 & 0.662 & Medium & 3.71 & 0.531 & High \\
\hline & 14 & Correct writing of the lesson's ideas & 2.67 & 0.844 & Medium & 2.79 & 0.955 & Medium \\
\hline & 15 & $\begin{array}{l}\text { Accuracy of linguistic wording and } \\
\text { addressing of the questions during the } \\
\text { lesson }\end{array}$ & 3.20 & 0.741 & High & 3.46 & 0.693 & High \\
\hline & 16 & $\begin{array}{l}\text { Ability to motivate while speaking } \\
\text { through the use of vocal pauses }\end{array}$ & 3.13 & 0.730 & High & 3.82 & 0.476 & High \\
\hline & 17 & $\begin{array}{l}\text { Ability to use a variety of tones } \\
\text { according to the educational situation }\end{array}$ & 2.97 & 0.669 & Medium & 3.29 & 0.763 & High \\
\hline & 18 & $\begin{array}{l}\text { Communication with learners in a clear } \\
\text { voice }\end{array}$ & 2.90 & 0.662 & Medium & 4.00 & 0.000 & High \\
\hline & 19 & $\begin{array}{l}\text { Ability to summarize the scientific terms } \\
\text { verbally }\end{array}$ & 3.37 & 0.669 & High & 3.82 & 0.476 & High \\
\hline & 20 & $\begin{array}{l}\text { Correcting the learners' mistakes while } \\
\text { teaching using the right terms }\end{array}$ & 2.93 & 0.740 & Medium & 3.75 & 0.788 & Medium \\
\hline Means Total & & & 3.01 & 0.356 & High & 3.59 & 0.349 & High \\
\hline \multirow[t]{5}{*}{ Assessment } & 21 & $\begin{array}{l}\text { Formulation of formative and summative } \\
\text { assessment questions in appropriate } \\
\text { language }\end{array}$ & 3.13 & 0.730 & High & 3.11 & 0.956 & High \\
\hline & 22 & $\begin{array}{l}\text { Appropriate summary of the lesson } \\
\text { contents }\end{array}$ & 3.00 & 0.788 & Medium & 3.61 & 0.737 & High \\
\hline & 23 & $\begin{array}{l}\text { Use of punctuation in activities and } \\
\text { exams }\end{array}$ & 2.13 & 0.819 & Low & 3.61 & 0.737 & High \\
\hline & 24 & $\begin{array}{l}\text { Provision of feedback to enhance } \\
\text { physical performance and skills }\end{array}$ & 2.87 & 0.681 & Medium & 3.71 & 0.731 & High \\
\hline & 25 & $\begin{array}{l}\text { Correction of the learners' oral and } \\
\text { written answers }\end{array}$ & 2.87 & 0.681 & Medium & 3.57 & 0.690 & High \\
\hline Means Total & & & 2.80 & 0.519 & Medium & 3.52 & 0.475 & High \\
\hline
\end{tabular}


It is clear from Table 4 that the pre-service physical education teachers' linguistic competencies in lesson planning, in general, require more training and development. However, the results of lesson implementation indicate that the pre-service physical education teachers achieved high grades close to those of the in-service physical education teachers in this area. The mean score of lesson implementation varied between $\mathrm{M}=3.01$ and 3.59.

This high mean score may be attributed to the specific nature of physical education lessons. In physical education lessons, the duration of the actual activity of the students must be more than the rest period of the lesson and not less than $70 \%$ of the total lesson time. Also, most of the active part of the lesson is performed by the learners and does not require much writing, which is the main source of linguistic mistakes. In the writing part of the lesson, the learners briefly write only the instructions of activities with some demonstrative diagrams (figures and graphs). The success of this part of the lesson depends on the teacher's management ability and the learners' interaction while doing the exercises. The high value of the mean score for the pre-service teachers' linguistic competency in lesson implementation can be also attributed to the good quality of the curriculum received by the population of this study during their academic training period. Most teaching method and school program curricula focus on providing pre-service teachers with a high level of lesson implementation competency, including the ability to transition between different parts of a lesson in a logical sequence and knowledge of different strategies and teaching methods. This approach allows the candidate to concentrate on these competencies and try to employ them with a high degree of accuracy.

As for the in-service physical education teachers' linguistic competencies, Table 4 shows that the mean scores for their linguistic competencies in lesson implementation was high (3.59). This can be attributed to the teachers' ability to link effectively between what they learned before starting their job and the educational reality during their teaching career, as well as their use of various teaching methods and strategies. Our results coincide with a previous study by Al-Rawahi and Al-Henaei (2013). Their results showed a high score in their population sample in the field of lesson implementation.

Despite the fact that the main requirements for the admission of students to a physical education department are clear articulation and a clear voice, the results shown in Table 4 for the pre-service teachers indicate that they have fewer linguistic competencies in planning $(\mathrm{M}=2.73, \mathrm{SD}=0.320)$ and assessment $(\mathrm{M}=2.8 ; \mathrm{SD}=0.519)$ than the in-service teachers, who have high scores in linguistic competencies in planning $(\mathrm{M}=3.45 ; \mathrm{SD}=0.410)$ and assessment $(\mathrm{M}=3.52 ; \mathrm{SD}=0.475)$. The results show that most of the population sample of the pre-service teachers encountered difficulties in the appropriate use of punctuation when writing instructions for activities and the correct use of linking words in the different paragraphs of the lesson. They also showed a weakness in writing the behavior objectives accurately.

This can be attributed to many reasons. Over time, curricula used to train physical education teachers focuses less on improving speaking and writing skills and more on the practical side of the field, which includes the use of rules and arbitration, some of which may be derived from foreign terms.

As for the weak composition of the behavior objectives among the in-service teachers, it is due to the indifference of the College of Education at Sultan Qaboos University toward composing specialized objectives. There is no specific course in the College of Education specialized in studying behavior objectives and how to specifically compose them. In the past, there was a course for objectives run by the Department of Educational Foundation and Administration at the College of Education. Recently, this course was cancelled, and the objectives were included in the curriculum course; this course can be taught by any lecturer, who may not have knowledge of physical education. Consequently, this will affect the linguistic composition of the correct objectives when planning lessons. Another reason is the Teaching Methods I and Teaching Methods II courses, which are taught at the College of Education. These courses do not focus on providing pre-service teachers the required linguistic competencies during their training period. In addition, there is no link between these courses and the four linguistic skills (listening, speaking, reading, and writing) in general or the writing skill in particular. This makes it difficult for the pre-service teachers to implement these skills during their training in school. These findings agree with the results of Al-Tawel and Al-Jaafreh (2017), which indicated that the competency of lesson planning had a lower mean score than other competencies.

As for the assessment part of the lesson, Table 4 shows that the pre-service teachers have fewer linguistic competencies than the in-service teachers. This can be attributed to many reasons. One of the reasons is that the pre-service teacher is not required to write the questions for the knowledge evaluation, while the in-service teachers must write theoretical questions in addition to the assessment of the Ministry of Education.

When carrying out a lesson, whether about teaching methods or practical exercises, the pre-service teacher is required to cover three behavioral goals: cognitive, skill related, and emotional. This is done through one oral 
question about the cognitive side, such as mentioning the technical steps of one of the skills that was studied in the lesson. Another question is used to examine the implementation of skills, and a third for carrying out the strategy for the emotional side.

Additionally, during their academic studies and before starting to teach, the pre-service teacher studies one course related to the evaluation of teaching, which is Measurement and Assessment course. This consists of three hours of theoretical teaching. This may be considered insufficient for the candidates to acquire the required competences.

On the other hand, the results show that the in-service teachers achieved high scores for linguistic competencies in the lesson assessment section. This is attributed to their accurate writing skills for different types of assessment methods, such as the preparation of written tests and students' individual reports. In addition, these in-service teachers attend training workshops organized by the Ministry of Education that focus on different types of assessment methods.

In any case, teacher training and qualification programs play a role in refining a teacher's abilities in lesson planning. Therefore, the in-service teachers achieved high scores in planning and assessment competencies in comparison to the pre-service teachers. This can be attributed to the training programs for new teachers. Workshops are provided for them that explain lesson planning, how to plan effectively, and what points they should consider, including correct linguistic composition and punctuation and how to write exercises properly. In-service teachers of physical education prepare only one lesson per term and therefore have fewer linguistic mistakes in their lesson plans.

There is also the professional development scheme for the in-service physical education teachers, which includes workshops run by Arabic language teachers that focus on writing Arabic correctly. These workshops help physical education teachers correctly write their lesson plans. There are also different sources of feedback that are issued regularly from the head teacher, the senior teacher, and the educational inspector. This largely helps the teachers acquire a good command of the language in the field of lesson planning. These results coincide with those of Stojanovic and Zdravkovic (2012), which indicated that teachers' scores in planning competencies are high.

However, the programs that are offered to new teachers last for one week only, and if we look in general at them, there are only a few, most of which are interested in the practical side more than the theoretical side. This is attributed to the nature of the subject, which has a more prominent practical side; also, the lesson is conducted by the in-service rather than the pre-service teacher during the training period. Hence, linguistic competencies are not of interest to the decision makers regarding the training programs for physical education teachers in general.

Our second research question investigated statistically significant differences in the linguistic competencies of pre-service female physical education teachers and teachers at the College of Education, Sultan Qaboos University, and in-service female physical education school teachers.

\subsection{Findings and Discussion Related to the Second Question}

To answer this question, the t-test was used to test the statistical significance between the mean scores of the responses provided by the pre-service female physical education teachers and the in-service female physical education school teachers in the linguistic competencies of the three fields.

Table 5. Descriptive statistics and results of t-tests for the linguistic competencies of pre-service and in-service teachers of physical education

\begin{tabular}{llllll}
\hline Linguistic Competencies Field & Arithmetic Mean & \multicolumn{2}{l}{ Standard Deviation } & \multirow{2}{*}{ (T) Value } \\
\cline { 2 - 5 } & $\begin{array}{l}\text { Pre-service } \\
\text { teachers }\end{array}$ & $\begin{array}{l}\text { In-service } \\
\text { teachers }\end{array}$ & $\begin{array}{l}\text { Pre-service } \\
\text { teachers }\end{array}$ & $\begin{array}{l}\text { In-service } \\
\text { teachers }\end{array}$ & \\
\hline Lesson Planning & 2.73 & 4.53 & 0.320 & 0.410 & $7.537^{*}$ \\
Lesson Implementation & 3.01 & 3.59 & 0.356 & 0.349 & $6.202^{*}$ \\
Lesson Assessment & 2.80 & 3.52 & 0.519 & 0.475 & $5.501 *$ \\
\hline
\end{tabular}

Table 5 shows that there are statistically significant differences at $\alpha<0.05$ between the mean scores of the student teachers of physical education and the in-service physical education teachers in linguistic competencies of the three fields (planning, implementation, and assessment). The following can be deduced:

1) The mean score of the pre-service teachers was 2.73 in the planning field, whereas the mean score of the in-service physical education teachers was 3.45 .

2) The mean score of in-service physical education teachers in the implementation field differed significantly from 
that of the pre-service teachers. In other words, the in-service teachers achieved significantly better results in the linguistic competencies of the implementation field than the pre-service teachers.

3) The mean score of the pre-service teachers in the assessment field was 2.80 , whereas the mean score of the in-service physical educational teachers in the assessment field was 3.52. This indicates that there was a statistically significant difference in favor of the in-service teachers.

We believe these differences exist for several reasons. First, the in-service physical teachers' teaching experience ranged from 2 to 10 years. Second, Arabic language workshops for in-service physical education teachers have a positive impact on the development of linguistic competencies compared to that of pre-service teachers. Third, professional development programs for in-service female teachers, whether in schools or at the Ministry of Education, increase linguistic and professional growth.

\subsection{Findings and Discussion Related to the Third Question}

Our third research question aimed to propose a framework for improving the linguistic competencies of pre-service physical education teachers at the College of Education, Sultan Qaboos University.The results of the study revealed that the linguistic competencies of pre-service physical education teachers were medium. We have developed a framework for developing Arabic language skills within the context of a college course, which includes the curriculum (social, cultural, psychological, and linguistic) and its components (objectives, content, competencies, teaching methods, and evaluation).

\section{1) Objectives}

The identification of general objectives is the first important step in building any course, and the basis for selecting the appropriate content of Arabic language skills and suitable methods to improve linguistic competencies. The objectives are:

- Affirming the Arab-Islamic identity among university students and enhancing their pride in the Arabic language.

- Strengthening students' national patriotism and enriching their mentality.

- Raising the level of linguistic performance of the university student in real-life situations and establishing a link between physical education and the Arabic language, as well as providing them with self-learning skills.

- Forming positive attitudes among the university students toward the Arabic language so that they will use it while speaking, listening, reading, and writing.

2) Linguistic Competencies

- Listening:

- Learning to glean important information from what is heard.

- Understanding the general meaning of the text through listening.

- Critiquing what is being heard according to logical criteria.

- Interpreting expressed ideas and opinions correctly.

- Summarizing what is being heard.

Speaking:

- Using standard Arabic in speaking.

- Articulating letters accurately.

- Distinguishing between closely related sounds.

- Arranging ideas logically so they are understood by the listener.

- Expressing ideas freely and eloquently.

- Speaking loudly and clearly.

- Using appropriate vocal pauses while speaking.

- Using proper accentuation and the right tone while speaking.

- Demonstrating the overall meaning through the context.

Reading:

- Reading text loudly in an expressive way. 
- Articulating letters accurately.

- Demonstrating sound representation of intended meaning.

- Inferring the main and secondary ideas from text.

- Guessing the meaning of new words from the context.

- Reading text at an appropriate pace while maintaining linguistic precision.

- Using grammatical rules correctly while reading text.

- Summarizing text accurately.

Writing:

- Using spelling rules while writing.

- Using grammatical rules while writing.

- Demonstrating clear handwriting.

- Maintaining the beauty of handwriting in terms of form, tidiness, and consistency, and harmony between letters, - words, and lines.

- Writing ideas to form complete and useful sentences.

- Using linking words correctly.

3) Content

The Arabic language skills course aims to provide students and teachers with knowledge, experience, and skills. The proposed content will be consistent with the objectives, flexible, and easy to assess. It will also enable the students to engage in dialogue, discussion, and extracurricular activities. It will enhance their teaching and learning skills as well as improve their knowledge and linguistic proclivities to meet their linguistic competency requirements.

4) Credit hours of the content

We recommend that the course consist of 30 credit hours varied between theory and practice so the students can apply what they have learned in theory and gain the desired benefits.

5) Teaching methods and associated activities

The reality of education stipulates that teaching methods depend on traditional methods, i.e., presentation and lecturing. Sometimes these methods might be accompanied by other methods, such as dialogue and discussion.

6) Assessment methods

An assessment is an essential requirement in every educational curriculum, and the assessment's success or failure be judged only through the results of an evaluation. The assessment of university students is designed to identify the difficulties they encounter while learning linguistic competencies in order to overcome these difficulties. Therefore, it is necessary to conduct an assessment of each competency that students learn while giving them a chance to make mistakes and try to correct them by themselves. In other words, the teacher should keep track of all activities carried out by students and give them useful feedback. As for the final assessment, its aim should not only be to enable students to pass the course in question but to ensure that they have acquired the necessary linguistic competencies and are able to apply them in the field.

\section{Recommendations}

We think that it is necessary to provide pre-service teachers of physical education at Sultan Qaboos University with appropriate linguistic skills courses. These courses should focus on their use of language as it relates to their planning, implementation, and assessment competencies. In addition, the program of the in-service physical education teachers in the Ministry of Education, which provides schools with teachers, should work on enhancing their linguistic competencies with planning, implementation, and assessment. It should include essay questions in physical education exams to give pre-service teachers a chance to demonstrate their linguistic competencies. There should be integration between the four language skills in order to raise the level of linguistic performance of pre-service physical education teachers at Sultan Qaboos University.

Finally, there is a need to conduct similar research studies that examine other specializations in the linguistic competencies. 


\section{References}

Abdl-Rashid, H. (2011). The effectiveness of reflective teaching on developing some necessary competencies for teachers of Arabic language bilingual students. Journal of Reading and Knowledge, 25, 153-194.

Abdul Rahim, A., \& Al-Shabatat, M. (2003). The use of Islamic education female students at Sultan Qaboos University of communication skills. Journal of Educational and Psychological Sciences, 3(4), 207-226.

Abu Harja, M., Zaghloul, M., \& Radwan, M. (2000). Encyclopedia of field training for sports education. The Book Center for Publishing.

Al-Naqah, M. (2010). The competency-based learning; its foundations and procedures. Al Tobji Printing Press.

Al-Rawahi, N., \& Al-Henaei, J. (2013). Instructional competencies of Omani physical education teachers and their relationship with reasons behind career choice. Journal of Educational and Psychological Sciences, 14(1), 513-538. https://doi.org/10.12785/JEPS/140118

Al-Tawel, A., \& Al Jaafreh, I. (2017). Competencies in physical education teaching: An investigation of teachers' perceptions in the southern Governorates of Jordan. Journal of Studies in Education, 7(2), 213-234. https://doi.org/10.5296/jse.v7i2.11262

Ali, M. (2009). Language proficiency for non-Arabic speakers: A guide to proficiency tests in Arabic language. United Arab Emirates University press.

Attia, M. (2007). Teaching Arabic in the light of performance competencies. Dar Al-Manhaag for publishing and distribution.

Baleed, S. (2009). The weakness of Arabic language in Algerian universities: Tezee-Wzo as a model. Hooma press.

Berry, B., \& Ginsberg, R. (1991). Effective schools and teacher professionalism: Educational policy at a crossroads. In J. Bliss, W. Firestone \& C. Richards (Eds.), Rethinking effective school: Research and Practice (pp. 138-153). Englewood Cliffs, NJ: Prentice Hall.

Breckett, A. (2004). Assessment of the specialization area in the program for Arabic language teachers' preparation of teachers' college in the light of the language skill efficiency required for teaching in the elementary schools. Unpublished master's thesis. Um Al Qura University, Kingdom of Saudi Arabia.

Dam, K. V., Schipper, M., \& Runharr, P. (2010). Developing a competency-based framework for teachers' entrepreneurial behavior. Teaching and Teacher Education, 26(9), 965-971. https://doi.org/10.1016/j.tate.2009.10.038

Davies, D., \& Rogers, M. (2000). Pre-service primary teachers' planning for science and technology activities: Influences and constraints. Research in Science and Technological Education, 18(2), 215-225. https://doi.org/10.1080/713694980

Hamdan, A. (2011). Teaching competencies necessary to prepare the teacher of physical education from their point of view. Journal of Science and Technology for Physical Activities, 8(8), 17-34.

Hamdan, M. (2001). Field practical education—concepts, competencies and practices. Modern Education House.

Hand, K. (2004). Building confident teachers: Preservice physical education teachers' efficacy balefires. Journal of Case Studies in Education, 6, 1-9.

Hattab, F. (2013). Factors of the low level of the Arabic language among students at Mohammed Khider Biskra University as a model. Unpublished master's thesis. Biskra University, Algeria.

Khair, A. (2014). The low level of the Arabic language at the college of Education, its effect and treatment proposals. Paper presented at the third Arabic language conference, Dubai. Abstract retrieved from http://www.alarabiahconference.org

Khazali, K., \& Momani, A. (2010). Teaching competencies among basic stage teachers in private schools in the light of their qualification, experience and specialization. University of Demashq Journal, 26(3), 553-592.

Madkour, A. (2011). Evaluation of preparation programs of non-Arabic speakers teachers. Arab Linguistic Series, AlRebat, Islamic Educational Scientific and Cultural Organization (ISESCO).

Marie, T. (2003). Explaining educational competencies. Al-Furqan publishing press.

Ministry of Education. (2009). Document of the Arabic language curriculum. Sultanate of Oman: Muscat.

Raslan, M. (1998). Language proficiency among secondary students (general-technical) and their attitudes toward Arabic language skills. Studies in Curriculum and Teaching Methods, 49, 121-157. 
Showaiter, I. (2004). Developing a training program based on educational learning competencies to prepare the teachers of social studies for the secondary stage in Jordan and its impact on practicing these competencies. Unpublished doctoral dissertation. Amman Arab University, Jordan.

Stojanovic, S., \& Zdravkovic, D. (2012). The self-assessment of personal competencies of physical education teachers. Physical Education and Sport, 10(2), 141-149.

Taima, R. (2006). The teacher; his competences, preparation and training. Dar AlFeker Press.

The Arab Bureau of Education for the Gulf States. (2010). Essential competencies of teachers. Kingdom of Saudi Arabia: Arab Centre for Educational Training for the Gulf States.

Wahabi, N. (2016). The low level of the Arabic language among university students: Causes and solutions. Journal of the Generation of Humanities and Social Sciences, 17, 171-183.

Zayton, K. (2003). Teaching (Its models and skills). Scientific office for publishing and distribution.

\section{Copyrights}

Copyright for this article is retained by the author, with first publication rights granted to the journal.

This is an open-access article distributed under the terms and conditions of the Creative Commons Attribution license (http://creativecommons.org/licenses/by/4.0/). 